\title{
Working conditions that contribute to absenteeism among nurses in a provincial hospital in the Limpopo Province
}

\author{
M Nyathi, MA Cur Student \\ University of South Africa
}

K Jooste, Associate Professor

University of Johannesburg

Keywords: absenteeism, workplace, nurses, working conditions
Correspondence address:

University of Johannesburg

Tel : (011) 5592857

Fax : (011) 5592257

E-mail : kjooste@uj.ac.za

\section{Abstract: Curationis 31(1): 28-37}

Absenteeism results in an increased workload for nurses who stand in for colleagues and can lead to situations in which a lack of motivation among nurses and a lowering of the quality of patient care may occur. The researcher observed that certain conditions, such as inflexible working schedules, were given as reasons for the absenteeism in units in a provincial hospital. A non-experimental, descriptive, quantitative study was undertaken. The purpose of the article was to describe the working conditions that contribute to absenteeism among the professional and sub-professional nurses at a provincial hospital in the Limpopo province of South Africa.

The sample included 107 professional nurses and 163 sub-professional nurses who voluntarily agreed to participate in the study. A questionnaire was used to collect data, which was analysed by using descriptive and inferential statistics.

The findings of this study indicated that personal and managerial characteristics, and organisational and working conditions may lead to absenteeism in the workplace. This article focuses on the working conditions that are constraints, namely inadequate group cohesion, inadequate delegation of autonomy, role ambiguity, ineffective routinisation and the effect of the workload in the workplace. Recommendations are made for improving working conditions to combat absenteeism among nurses. The limitations of this study are highlighted.

\section{Introduction}

Absenteeism of nurses leads to an increased staff shortage in health care institutions (Borda \& Norman, 1997:385). Nurse managers may then experience difficulties in altering work schedules and reallocating the nursing tasks of those who are absent from work to the nurses who are present, to ensure the continuity of patient care in the unit. A nurse allocated to stand in for an absent colleague may be unfamiliar with the tasks to be performed. He or she may need orientation and more supervision from the unit manager to perform newly allocated tasks (Gaudine \& Saks, 2001:15). This study was conducted by means of an instrument to explore and describe the factors related to absenteeism in a provincial hospital in the Limpopo Province. One of the main reasons for absenteeism that came to the fore was the working conditions of nurses in the workplace

Absenteeism and the resultant increased workload for nurses who stand in for absent colleagues could lead to a situation in which patient care is provided under pressure, thereby lowering the quality of patient care 
(McHugh, 2001:5). The remaining nurses experience work-related stress, which adversely affects their morale. This may, in turn, cause absenteeism (Sarudi, 2000:14). The inevitable outcome of this is that various tasks are not completed and that scheduled deadlines are missed (McHugh, 2001:5).

Knowledge of various managerial strategies to deal effectively with absenteeism is essential for nurse managers. This study makes recommendations that could assist nurse managers in the Limpopo Province of South Africa to manage absenteeism in the workplace.

Working conditions may contribute to absenteeism of nurses in the workplace. According to De Boer, Bakker, Syroit and Schaufeli (2002:182), working conditions, such as assignment to scheduled working hours and reallocation to substitute for absent colleagues, contribute to absenteeism of nurses in the workplace. In Florida, the research study by Kass, Vodanovich and Callender (2001:318) revealed that repetitive tasks cause boredom, which contributes to absenteeism.

Across Europe, health care organisations have high rates of reported illness absence among nurses in the workplace (Time, 2003:42). In British hospitals, where nurses are overworked and underpaid, the culture of sickness absenteeism allegedly costs the government billions of pounds. British hospitals are also faced with poor staffing levels, which are often aggravated by a high rate of absenteeism among nurses (Payne, 1999:14). Nurses work under the constant threat of public violence and criticism. Nurses are often abused both verbally and physically by patients and their relatives. The public also blames nurses, through the media, for the decline in the quality of patient care in hospitals (Wills, 1999:21; Wing, 1999:24).

The same is true of South African health care institutions, where work-related issues such as low pay, the lack of incentives and poor working conditions demoralise nurses and contribute to absenteeism (Mgomezulu, 2000:30; Mzolo, 2001:38). Bydawell (2000:16) found that in South Africa, physical exhaustion due to work pressure could also lead to absenteeism.
From the above discussions, it is clear that absenteeism among nurses in the workplace is both a national and an international problem, and that it has dire consequences. A questionnaire based on an intensive literature study was developed to explore the working conditions that contribute to absenteeism in the nursing work environment. The working conditions that contribute to absenteeism are identified to be addressed and ways to combat this problem are recommended.

\section{Research problem}

From national and international literature, it is evident that absenteeism among nurses is a problematic issue. The researcher has also observed a tendency to absenteeism among nursing staff in the surgical unit where she works as a unit manager. While research has been conducted elsewhere to identify the different factors that contribute to absenteeism among nurses, the factors that are at play in a provincial hospital of the Limpopo province have not been investigated and formally documented. The specific reasons for absenteeism due to working conditions in the units in this provincial hospital are unclear.

Both the nursing staff and the patients in this hospital experience the consequences of poorly managed absenteeism. The consequences include a strain on the staff budget, an increased workload for those who do report for duty and a deterioration in the quality of patient care provided.

The effective management of absenteeism depends on knowledge of the factors that contribute to it. The absence of this information impacts negatively on efforts to establish strategies to manage absenteeism, effective staff utilisation, staff productivity and harmony in the units The problem statement, stated in interrogative form, is:

Which characteristics contribute to absenteeism among nurses in this provincial hospital in the Limpopo Province?

\section{Purpose}

The purpose of the study was to explore and describe working conditions that contribute to absenteeism among the nursing staff of a provincial hospital in the Limpopo Province of South Africa. This resulted in recommendations that could be used by nurse managers to combat absenteeism among nurses in this provincial hospital.

\section{Research questions}

The study explores the following research questions:

\section{- Which characteristics of the nurse contribute to absenteeism? \\ - Which characteristics of the nurse manager contribute to absenteeism? \\ - Which organisational characteristics contribute to absenteeism? \\ - Which norking conditions contribute to absenteeism?}

This article provides the findings on the working conditions that contribute to absenteeism among nurses in the Limpopo province.

\section{Research design}

A quantitative, descriptive study was conducted to investigate and describe the working conditions that contribute to absenteeism among nurses in the workplace. This design supports the collection of numerical data by using a structured, self-report instrument, and statistical data analysis (Polit \& Hungler, 1997:466).

\section{Method}

A survey was conducted with a structured questionnaire and the total accessible population of 107 professional and 163 sub-professional nurses was invited to partake in the study. Total sampling was introduced as data was intended to be collected from the whole population of nurses in one provincial hospital. By including the whole assessable population the findings could be generated to the specific provincial hospital. A total of 233 professional and sub-professional nurses were willing to voluntarily participate in this study.

The questionnaire (Afrikaans and English) comprised five sections on biographical information, as well as characteristics of the nurse and manager, and conditions of the work and organisation (Polit \& Hungler, 1997:335). The items were derived from the literature 
review. The biographical section elicited responses that were measured on the nominal and ordinal levels of measurement. All the other items comprised Likert Scales, and therefore the ordinal level of measurement was applicable. In this study respondents had to indicate their level of agreement with each item by responding with the "to no extent", "to a limited extent", "to a moderate extent" or "to a large extent" options.

Section A was designed to obtain background information on the age of nurses, gender, marital status, highest qualifications, registration with the South African Nursing Council, years of experience, the clinical ward/unit in which the nurse was working and the current post held by the respondent.

Section B aimed to investigate the extent to which the respondents were of the opinion that various reasons related to the characteristics of nurses contribute to absenteeism among nurses. Section $\mathrm{C}$ aimed to determine the extent to which the respondents believed that the characteristics of the manager contributed to their absenteeism. Twenty-two items on the leadership style of the manager were formulated here. Section D comprised items about characteristics of the work in relation to autonomy, routinisation and group cohesion. The purpose was to find out the extent to which nurses believed that these aspects contribute to absenteeism. Twenty-five items were formulated in this regard. This article focuses on the data obtained from section $D$ of the instrument.

Section E was designed to identify the extent to which respondents believed that the characteristics of the organisation contribute to absenteeism, with the focus on decentralisation, the absence management policy, promotion opportunities, career development, incentives, remuneration, facilities and manpower. Twenty items were developed in this regard.

The newly developed questionnaire was pre-tested before the data collection began. The purpose of pre-testing the questionnaire was to test its face and content validity, and to identify and rectify problem areas (Brink \& Wood, 1998:373). After pre-testing the instrument, it was refined. The participants who took part in pre-testing the questionnaire were not included in the major study (Brink \& Wood, 1998:259).

The questionnaires were personally distributed by trained field workers who requested every professional nurse to complete his/hers by a specific date. Appointments were made to collect the completed questionnaires placed in sealed envelopes.

Quantitative data analysis was performed by a statistician and descriptive statistical methods were employed. A factor analysis of all the items listed in the questionnaires was performed to identify constructs within the different sections of the questionnaire (main factors of absenteeism) that would guide the discussion (Burns \& Grove, 2003:542).

The chi-square test was performed to measure the degree of association and the significance of the responses made by the two groups of respondents regarding absenteeism. The chi-square $\left(\div^{2}\right)$ test was done to determine whether responses about the reasons for absenteeism could be associated with, for instance, the age of the nurses and their professional categories. A significance level of $p<0.05$ was considered for this study (Burns \& Grove, 2003:499).

\section{Validity and reliability in the research study}

Validity is the degree to which an instrument measures what it is intended to measure (Polit \& Hungler, 1997:656). Content validity was ensured by the instrument representing all the different components of the variables to be measured, as debated in the literature review (Brink, 1996:168). As recommended by Brink and Wood (1998:271), content validity was ensured by the completeness with which items cover the important areas of absenteeism. The questionnaire was tested for face validity during the pre-testing of the instrument. It was determined whether the items adequately represented the aspects associated with absenteeism of nurses.

The questionnaire was also tested for reliability and, specifically, for internal consistency. The Chronbach Alpha scores of the factors identified in the factor analysis (Table 1) indicated the degree of consistency or dependability with which the instrument measured absenteeism among nurses (Polit \& Hungler, 1997:347).

In this research study, external validity was enhanced because the entire population was involved in data collection.

\section{Ethical considerations}

Prior to obtaining informed consent from the respondents, the researcher explained the nature and purpose of the study to the participants. The respondents were assured that no harm would befall them for revealing their reasons for absenteeism in the workplace. They were assured that the recommendations of the study might contribute towards a better working environment. As Burns and Grove (2003:94) suggest, the respondents were informed that participation in the research study was voluntary and that failure to comply would not result in any penalties. They were assured that they could withdraw even after consenting to cooperate in the research. The respondents were furnished with contact information, so that they could contact the unit manager or the researcher in the event of further questions, comments or complaints.

Confidentiality and anonymity (Burns \& Grove, 2003:99) were very important in this study, as absenteeism is a sensitive issue. The respondents who were often absent from work might be reluctant to respond to the items because they might feel that the questionnaire was designed to examine their behaviour. The respondents were informed that they should not write their names on the questionnaires and that the raw data would be entered into the computer using codes. They were assured that neither their names nor that of the hospital would appear in the research report. Permission to conduct the research study was obtained from the Hospital manager of the provincial hospital in the Limpopo Province and the Head of the Department of Health and Welfare. The researcher agreed to disseminate the research results to the authorities.

Scientific integrity refers to the degree to which a study is methodologically and conceptually sound, a major criterion for research utilisation (Burns \& Grove, 2003:218; Polit \& Hungler 1997:468). In 
this study, the research method and conceptual definitions were approved by the supervisor and the co-supervisor. Scientific integrity was maintained through the acknowledgement of all sources in the literature review. Data was collected after the supervisors had approved the instrument, and the instrument had been tested for its validity and reliability. During data analysis, appropriate tests were used and there was no manipulation of statistics or distortion of findings to support the researcher's opinions. A statistician assisted with data analysis.

\section{Working conditions}

Two hundred and thirty-three $(n=233)$ nurses participated in the survey, representing professional $(41.6 \% ; n=97)$ and sub-professional $(58.3 \% ; \mathrm{n}=136)$ nurses from one regional hospital. Respondents were mainly females $(83.2 \% ; n=194)$, with a mean age of 40 years. Approximately half of the respondents $(50.2 \% ; \mathrm{n}=117)$ were married, and the other half $(49.7 \% ; n=116)$ unmarried. Respondents had an average of 14.1 years of nursing experience, working in various speciality fields in the work setting.

The following discussion will address the research question that stated:

- Which working conditions contribute to absenteeism among nurses?
The factor analysis resulted in five factors or reasons for absenteeism due to working conditions, namely inadequate group cohesion, inadequate delegation of autonomy, role ambiguity, ineffective routinisation and the effect of workload in the workplace.

Significant differences in the responses of
- the professional and sub- professional nurses, and
- $\quad$ nurses younger than 40 and those who are 40 years and older

that were identified in these factors will also be outlined. The discussions will not focus on the factors, but on the items within the factors.

\section{Inadequate group cohesion}

Factor 1 (á 0.8233 ) comprises reasons for absenteeism that are classified under group cohesion because it deals with group dynamics and social relations among group members in the workplace. Group behaviour, such as the lack of a culture of work attendance among peers, tolerance for absenteeism in the case of some nurses in the unit and the lack of work ethics among nurses in the unit (item 6) can also lead to absenteeism. Saksvik and Nytro (2001:17) point out that nurses with low personal work ethics have no sense of responsibility towards their work and have the tendency to be absent from work without valid reasons.
Significant differences that resulted from the items on inadequate group cohesion

As group cohesion increases, the levels of absenteeism decrease (Gellatly \& Luchak, 1998:1087). Shader, Broome, Broome, West and Nash (2001:210) state that decreased levels of group cohesion and high rates of absenteeism prevail among groups who are exposed to inflexible working schedules.

\section{- $\quad$ Tolerance for absenteeism in} the case of some nurses in the unit

Table 1 indicates significant differences between the responses of the subprofessional and the professional nurses to tolerance for absenteeism.

Of the 45 respondents who indicated that nurses are, to a moderate extent, absent from work due to tolerance of absenteeism in the case of some nurses in the unit, $33(73.3 \%)$ were subprofessional and $12(26.6 \%)$ were professional nurses. Differences in opinion occurred as 80 respondents, 53 (66.2\%) of whom were sub-professional compared to $27(33.7 \%)$ who were professional nurses, indicated that tolerance does not at all contribute to absenteeism. It is concluded that the subprofessional nurses are significantly less inclined than the professional nurses to believe that absence from work is due to tolerance of absenteeism in the case of some nurses in the unit. Glaudine and Saks (2001:28) state that the lack of

\section{Table 1: Nurses are absent from work because of tolerance for absenteeism in the case of some nurses in the unit ( $n=229$ responses)}

\begin{tabular}{|l|l|l|l|}
\hline Item & \multicolumn{2}{|l|}{ Professional category } & Total responses \\
\hline $\begin{array}{l}\text { Tolerance of absenteeism in the case of } \\
\text { some nurses in the unit }\end{array}$ & $\begin{array}{l}\text { Sub-professional } \\
\text { nurses }\end{array}$ & $\begin{array}{l}\text { Prof e s s i o n a l } \\
\text { nurses }\end{array}$ & n \% \\
\hline Not at all & $\mathbf{5 3 ( 6 6 . 2 \% )}$ & $\mathbf{2 7}(\mathbf{3 3 . 7 \%})$ & $\mathbf{8 0}(\mathbf{1 0 0 . 0 \% )}$ \\
\hline To a limited extent & $26(50.0 \%)$ & $26(50.0 \%)$ & $52(100.0 \%)$ \\
\hline To a moderate extent & $\mathbf{3 3}(\mathbf{7 3 . 3 \%})$ & $\mathbf{1 2 ( 2 6 . 6 \% )}$ & $\mathbf{4 5 ( 1 0 0 . 0 \% )}$ \\
\hline To a large extent & $24(46.1 \%)$ & $28(53.8 \%)$ & $52(100.0 \%)$ \\
\hline & & & $229(100.0 \%)$ \\
\hline 4 missing values & & & \\
\hline
\end{tabular}

$\stackrel{2}{\rightarrow}=10.867 ; \mathrm{df}=3 ; \mathrm{p}<0.012$ 
Table 2: Nurses are absent from work because of the lack of a culture of work attendance among peers $(n=230$ responses)

\begin{tabular}{|l|l|l|l|}
\hline Item & \multicolumn{2}{|l|}{ Professional category } & Total responses \\
\hline $\begin{array}{l}\text { Lack of a culture of work attendance } \\
\text { among peers }\end{array}$ & $\begin{array}{l}\text { Sub-professional } \\
\text { nurses }\end{array}$ & $\begin{array}{l}\text { Pro fe s i o n a l } \\
\text { nurses }\end{array}$ & n \% \\
\hline Not at all & $73(\mathbf{6 8 . 8 \% )}$ & $33(\mathbf{3 1 . 1} \%)$ & $\mathbf{1 0 6} \mathbf{( 1 0 0 . 0 \% )}$ \\
\hline To a limited extent & $25(55.5 \%)$ & $20(44.4 \%)$ & $45(100.0 \%)$ \\
\hline To a moderate extent & $18(\mathbf{4 5 . 0 \% )}$ & $22(\mathbf{5 5 . 0 \% )}$ & $\mathbf{4 0 ( 1 0 0 . 0 \% )}$ \\
\hline To a large extent & $20(51.2 \%)$ & $19(48.7 \%)$ & $39(100.0 \%)$ \\
\hline & & & $230(100.0 \%)$ \\
\hline 3 missing values & & & \\
\hline
\end{tabular}

$\stackrel{\div}{\div}=8.696 ; \mathrm{df}=3 ; \mathrm{p}<0.034$

absenteeism feedback to extreme offenders contributes to absenteeism in the unit. They also point out that absentees should be given feedback about their own number of absent days as compared with their peers.

\section{- $\quad$ The lack of a culture of work} attendance among peers

A culture of work attendance is learned through interactions with peers in the workplace. Individuals experience social pressure to lower their absence to a group norm or the culture of the group. Of the 40 respondents who indicated that nurses are absent from work to a moderate extent due to the lack of a culture of work attendance among peers, $18(45.0 \%)$ were sub-professional and $22(55.0 \%)$ were professional nurses. The significant difference in opinion occurred as 73 $(68.8 \%)$ sub-professional nurses, compared to $33(31.1 \%)$ professional nurses did not attribute absenteeism to this reason at all. It is apparent that the sub-professional nurses are significantly less inclined than the professional nurses to believe that nurses are absent from work because of the lack of a culture of work attendance among peers. The results of this study could be viewed within the context of the findings of Gellatly and Luchak (1998:1086), which revealed that an individual's absenteeism behaviour is affected to varying degrees by the collective behaviour of others.

\section{Delegation of autonomy}

Factor 2 (á 0.7895 ) comprises reasons for absenteeism that are classified under inadequate delegation of autonomy because it deals with nurses making decisions on their own or performing functions independently, irrespective of their abilities. According to Adams and Bond (2000:541), knowledgeable nurses who possess a variety of skills prefer to be autonomous. However, if nurses lack the necessary skills, autonomy can become threatening and lead to absenteeism. Nurses may engage in absenteeism behaviour because they have to do a number of things in the workplace, and have to do a job that requires more skills than they have.

\section{Significant differences in response to delegation of autonomy}

McGilton and Pringler (1999:259) mention that competency assessment to determine the capability of nurses who are expected to make decisions is a critical feature before the delegation of responsibilities occurs. According to Grant, Nolan, Maguire and Melhuish (1996:817), very few nurses are in favour of autonomy in the workplace. The said authors add that nurses who are not in favour of autonomy might feel that too many responsibilities are delegated to them. They may be inclined to perceive autonomy as a burden.

\section{- Nurses have to do a job that requires more skills than they have}

Table 3 indicates significant differences between the responses of the subprofessional and the professional nurses to doing a job that requires more skills.

Of the 40 respondents who indicated that nurses are, to a moderate extent, absent from work because they have to do a job that requires more skills than they have, $28(70.0 \%)$ were sub-professional nurses compared to only $12(30.0 \%)$ professional nurses. Of the 88 respondents who attributed absenteeism to these skills requirements to a large extent, $58(65.9 \%)$ were sub-professional nurses and 30 $(34.0 \%)$ professional nurses. It may be concluded that the sub-professional nurses are significantly more inclined than the professional nurses to believe that nurses are absent from work due to doing a job that requires more skills than they have. Hemingway and Smith (1999:295) state that owing to the lack of clarity regarding job responsibilities, junior nurses are often allocated duties that they are not trained or qualified to do. These discrepancies contribute to absenteeism.

\section{Role ambiguity}

Factor 3 (á 0.7877 ) comprises reasons for absenteeism that are classified under role ambiguity because it indicates that nurses lack clarity on how they are expected to perform their duties and that they are dissatisfied with the shifts. Van der Walt (1999:50) mentions that nurses working night shift have a higher rate of absenteeism than those working day shift. Having to work fluctuating shifts can lead to a sense of dissatisfaction among nurses. 
Table 3: Nurses are absent from work because they have to do a job that requires more skills than they have ( $n=230$ responses)

\begin{tabular}{|l|l|l|l|}
\hline Item & \multicolumn{2}{|l|}{ Professional category } & Total responses \\
\hline $\begin{array}{l}\text { They have to do a job that requires more } \\
\text { skills than they have }\end{array}$ & $\begin{array}{l}\text { Sub-professional } \\
\text { nurses }\end{array}$ & $\begin{array}{l}\text { Prof e s s i o n a l } \\
\text { nurses }\end{array}$ & n \% \\
\hline Not at all & $35(54.6 \%)$ & $29(45.3 \%)$ & $64(100.0 \%)$ \\
\hline To a limited extent & $15(39.4 \%)$ & $23(60.5 \%)$ & $38(100.0 \%)$ \\
\hline To a moderate extent & $28(\mathbf{7 0 . 0 \% )}$ & $12(30.0 \%)$ & $\mathbf{4 0}(\mathbf{1 0 0 . 0 \% )}$ \\
\hline To a large extent & $58(65.9 \%)$ & $30(34.0 \%)$ & $\mathbf{8 8 ( 1 0 0 . 0 \% )}$ \\
\hline & & & $230(100.0 \%)$ \\
\hline 3 missing values & & & \\
\hline
\end{tabular}

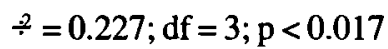

\section{Significant differences in response to role ambiguity}

Independence is supported by role clarification and access to information. Bennett (2002:6) holds the view that nurses, who are not given an opportunity to use their own initiative, perceive their work as boring and lacking motivating potential. This contributes to low morale and absenteeism in the workplace.

\section{- They have to work fluctuating} shifts in the workplace

Table 4 indicates significant differences between the responses of nurses younger than 40 and those who are 40 years and older on working fluctuating shifts.

Of the 45 respondents who indicated that nurses are, to a large extent, absent from work due to having to work fluctuating shifts in the workplace, 28 (62.2\%) respondents were younger than 40 years of age, and $17(37.7 \%)$ were 40 years and older. Absenteeism was, to a moderate extent, attributed to having to work fluctuating shifts in the workplace by 43 respondents, $26(60.4 \%)$ of whom were younger than 40 years and $17(39.5 \%)$ of whom were 40 years and older. It is apparent that nurses who were 40 years and younger were significantly more inclined than nurses who were 40 years and older to attribute absenteeism to fluctuating shifts. This finding indicates that fluctuating shifts are unlikely to be tolerated by younger nurses, especially those who place a high value on control over their own time. Fluctuating shifts decrease the morale of nurses and contribute to absenteeism and staff turnover in the workplace.

\section{- They have to perform duties} without a job description

Table 5 indicates significant differences between the responses of the subprofessional and the professional nurses on performing duties without a job description. Of the 54 respondents who indicated that nurses are, to a large extent, absent from work due to having to perform duties without a job description, $38(70.3 \%)$ were younger than 40 years, and $16(29.6 \%)$ were 40 years and older. Absenteeism was attributed, to a moderate extent, to having to perform duties without a job description by 27 respondents, $14(51.8 \%)$ of whom were younger than 40 years and $13(48.1 \%)$ of whom were 40 years and older. It may be concluded that nurses younger than $\mathbf{4 0}$ years are significantly more inclined to believe that absence from work is due to having to perform duties without a job description than nurses who are 40 years and older. This finding indicates that younger nurses are more prone to experiencing role ambiguity than the older nurses. Hemingway and Smith (1999:286) state that role ambiguity, owing to a lack of clarity regarding job responsibility, contributes to absenteeism in the workplace. Rowland and Rowland (1997:525) state that during orientation and after nurses have received a job description, they develop a preconception of what the job entails. If the nurses' expectations are different from the job demands, they may lose interest in the job and resort to absenteeism.

\section{Ineffective routinisation}

Factor 4 (á 0.6954) comprises reasons for absenteeism that are classified under ineffective routinisation because they deal with the daily operational activities in the workplace. Various reasons for absenteeism in the workplace are associated with unit routine. According to Johnson and Indvik (1997:2), monotonous jobs with no room for creativity can lead to a low morale and the absenteeism of nursing staff. Kass et al. (2001:319) state that those repetitive tasks that under-utilise one's ability lead to feelings of boredom and fatigue, which result in absenteeism of nurses in the workplace. Rowland and Rowland (1997:524) state that if the individual's capacity is systematically under-utilised, one may find the job boring and this may lead to absenteeism. No significant responses to items in factor 4 were identified.

\section{Effect of workload in the workplace (factor 5)}

Factor 5 (á 0.6627 ) comprises reasons for absenteeism that are classified under effect of workload in the workplace because it indicates that nurses are doing more than is expected, which results in their experiencing work pressure. Various reasons for absenteeism are associated 
Table 4: Nurses are absent from work because they have to work fluctuating shifts in the workplace ( $n=226$ responses)

\begin{tabular}{|l|l|l|l|}
\hline Item & \multicolumn{2}{|l|}{ Professional category } & Total responses \\
\hline $\begin{array}{l}\text { They have to work fluctuating shifts in } \\
\text { the workplace }\end{array}$ & $\begin{array}{l}\text { Younger than } 40 \\
\text { years }\end{array}$ & $\begin{array}{l}\text { Forty (40) years } \\
\text { and older }\end{array}$ & n \% \\
\hline Not at all & $54(59.3 \%)$ & $37(40.6 \%)$ & $91(100.0 \%)$ \\
\hline To a limited extent & $25(53.1 \%)$ & $22(46.8 \%)$ & $47(100.0 \%)$ \\
\hline To a moderate extent & $26(60.4 \%)$ & $17(39.5 \%)$ & $\mathbf{4 3 ( 1 0 0 . 0 \% )}$ \\
\hline To a large extent & $28(62.2 \%)$ & $17(37.7 \%)$ & $\mathbf{4 5 ( 1 0 0 . 0 \% )}$ \\
\hline & & & $226(100.0 \%)$ \\
\hline 7 missing values & & & \\
\hline
\end{tabular}

$\stackrel{?}{\div}=7.786 ; \mathrm{df}=3 ; \mathrm{p}<0.051$

with workload. These reasons may include long working hours and nurses being subjected to alarming workload levels. Burke and Greenglass (2000:170) state that missing tea breaks and being subject to a high workload can increase nurses' stress levels and this may, in turn, lead to absence from work.

No significant responses to the items in factor 5 were identified.

\section{Findings and conclusions}

The respondents identified five factors associated with working conditions that may contribute to absenteeism, namely inadequate group cohesion, inadequate delegation of autonomy, role ambiguity, ineffective routinisation, and the effect of the workload in the workplace.

Within these factors, significant differences of opinion between the professional and sub-professional nurses, and nurses younger than 40 and those who are 40 years and older were identified on certain items. These items should seriously be considered as working conditions that lead to absenteeism. The following items are thus a cause for concern:

\section{- Ineffective group cohesion}

The results of this study indicate that there are differences of opinion on the extent to which ineffective group cohesion contributes towards absenteeism. The sub-professional nurses were less inclined than the professional nurses to indicate that nurses are absent from work because of tolerance of absenteeism in the unit, and because of the lack of a culture of work attendance among peers. Erickson, Nicholson and Ritter (2000:265) state that absenteeism is higher in some work units that reflect tolerance of excessive absenteeism in the workplace, and lower in a workgroup where absenteeism is frowned upon. In this study, the subprofessional nurses were more in agreement with this statement than the professional nurses.

\section{- Delegation of autonomy}

Within the delegation of autonomy factor, significant differences of opinion on the extent to which skills requirements contribute towards absenteeism were obtained. The sub-professional nurses were more inclined than the professional nurses to indicate that nurses are absent from work because they have to do a job that requires more skills than they have. Allgood, O'Rourke, Van Derslice and Hardy (2000:757) mention that autonomy contributes more to absenteeism among nurses with lower educational qualifications than those with higher qualifications. The findings indicated that the sub-professional nurses are more in agreement with this statement than the professional nurses.

\section{- $\quad$ Role ambiguity}

Within the role ambiguity factor, significant differences on the extent to which role ambiguity contributes towards absenteeism were identified.

Nurses younger than 40 years were significantly more inclined than nurses who are 40 years and older to indicate that absenteeism is due to having to work fluctuating shifts and to perform duties without a job description. Van der Walt (1999:50) states that shift work contributes to absenteeism. Collins, Jones, McDonnell, Read, Jones and Cameron (2000:10) reveal that working without job descriptions results in dissatisfaction and contributes to absenteeism, due to the lack of clarity regarding job responsibilities. McNeeseSmith (1997:53) mentions that commitment depends on the nurse's role clarity in the workplace. Nurses who experience role conflict in their workplace demonstrate inadequate work commitment and have high rates of absenteeism. The findings indicate that younger nurses are more in agreement with these views than nurses who are 40 years and older.

Regarding the factors ineffective routinisation and the effect of workload in the workplace) neither of the items revealed significant differences between the responses of the specified groups of respondents. It is therefore concluded that ineffective routinisation and the effect of workload in the workplace are inconsequential with regard to absenteeism. The latter is also confirmed by Pousette and Hanse (2002:246) who found no significant relationship between absenteeism among nurses and 


\begin{tabular}{|l|l|l|l|}
\hline Item & \multicolumn{2}{|l|}{ Professional category } & Total responses \\
\hline $\begin{array}{l}\text { They have to perform duties without a } \\
\text { job description }\end{array}$ & $\begin{array}{l}\text { Younger than } 40 \\
\text { years }\end{array}$ & $\begin{array}{l}\text { Forty (40) years } \\
\text { and older }\end{array}$ & $\mathrm{n} \%$ \\
\hline Not at all & $38(40.4 \%)$ & $56(59.5 \%)$ & $94(100.0 \%)$ \\
\hline To a limited extent & $26(51.9 \%)$ & $25(49.0 \%)$ & $51(100.0 \%)$ \\
\hline To a moderate extent & $\mathbf{1 4}(\mathbf{5 1 . 8 \% )}$ & $\mathbf{1 3}(\mathbf{4 8 . 1 \% )}$ & $\mathbf{2 7 ( 1 0 0 . 0 \% )}$ \\
\hline To a large extent & $\mathbf{3 8}(\mathbf{7 0 . 3 \%})$ & $\mathbf{1 6}(\mathbf{2 9 . 6 \% )}$ & $\mathbf{5 4 ( 1 0 0 . 0 \% )}$ \\
\hline & & & 226 \\
\hline 7 missing values & & & \\
\hline
\end{tabular}

$\div=12.316 ; \mathrm{df}=3 ; \mathrm{p}<006$

workload

\section{Recommendations}

It is necessary to alleviate the work pressure that nurses perceive by creating an organisational culture of work attendance.

It is recommended that the organisation should:

- $\quad$ analyse absenteeism rates in the different units to establish the reasons why nurses and managers accept a culture of absenteeism;

- $\quad$ recruit and hire adequately motivated nurses: such recruitment could be done by offering career exhibitions at schools, and developing and implementing a sound marketing strategy; and

- $\quad$ have effective and informative induction programmes for newly appointed nurses to establish a partnership between employee and employer that addresses individual needs.

It is recommended that the nurse manager should:

- $\quad$ establish a shift system that supports manageable working hours in terms of length and practicality, considering the needs of the units and the circumstances of the nurse; consider the option of introducing flexi-time systems that would allow nurses to choose their starting time and their quitting times, but within the constraints of specified core hours and the required number of hours per week to be worked (Baguma 2001:196);

- evaluate new on-duty working hour systems that are suitable to allow nurses time off to attend to their family and personal needs. Another option would be to introduce flexible shift allocation practices by allowing full-time nurses to switch temporarily to part-time status or to an alternative shift, whichever suits their circumstances (Kay, 1999:50). Alternatively, nurses could be allowed to proactively pursue negotiations among one another, or even exchange their work schedules in order to meet their needs (Qureshi, 2000:175); advise nurses to alternate their long annual leave with frequent short vacations when they feel tired and need rest. At least ten days' leave could be sufficient to alleviate stress (Westman \& Etzion, 2001:604).

In the interests of the effective management of absenteeism, it is recommended that further research be conducted to determine why different categories and age groups of nurses differ in their opinions on the working conditions that lead to absenteeism.

\section{Limitations of the study}

Smaller samples tend to reduce the likelihood that the sample is representative of the population being studied (Polit \& Hungler, 1997:240). The research was conducted in one provincial hospital in the Limpopo province. The findings can therefore be applied only to the specific hospital in this province.

\section{Summary}

Absenteeism is likely to be the result of a culture of acceptance of the absenteeism trend, possibly due to an environment that is tolerant towards absenteeism, the lack of peer group pressure from colleagues and nurse managers to attend work, and the inability of the nurse manager to address the problem of absenteeism in the workplace.

It is also concluded that the management of absenteeism in the workplace is being hampered by differences in opinion between sub-professional and professional nurses on skills deficit, as manifested by having to do a job that requires more skills than they have.

It is furthermore concluded that the management of absenteeism in the workplace is being hampered by differences in opinion between nurses younger than 40 years and nurses who are 40 years and older on role ambiguity, as manifested by having to work fluctuating shifts and working without job descriptions.

This study has highlighted which work- 
related factors contribute to absenteeism, as perceived by the respondents. Instances where there are differences of opinion on the extent to which some factors contribute to absenteeism were also identified. The recommendations are aimed at assisting organisations and managers in reducing absenteeism in the workplace, and in so doing, improving the quality of care.

\section{References}

ADAMS, A \& BOND, S 2000: Hospital nurses' job satisfaction, individual and organizational characteristics. Journal of Advanced Nursing. 32(3): 536-543.

\section{ALLGOOD, C; O'ROURKE, K; VAN} DERSLICE, J \& HARDY, MA 1999: Job satisfaction among nursing staff in a military health care facility. Military Medicine, 165(10): 757-761.

BAGUMA, P 2001: Predictors of absenteeism among Ugandan public officers. Journal of Psychology in Africa. 11(2): 185-199.

BENNETT, H 2002: Employee commitment: the key to absence management in local government? Leadership and Organizational Development Journal. 23(8): 1-19.

BORDA, RG \& NORMAN, IJ 1997: Testing a model of absence and intent to stay in employment: a study of registered nurses in Malta. International Journal of Nursing Studies. 34(5): 375-384.

BRINK, HI 1996: Fundamentals of research methodology for health care professionals. Cape Town: Eppindust II.

BRINK, PJ \& WOOD, MJ 1998: Advanced design in nursing research. Thousand Oaks: Sage.

BUNCHAN, J \& O'MAY, F 1998: Nursing supply and demand: Reviewing evidence. Nursing Times. 94(26): 60-63.

BURKE, RJ \& GREENGLASS, ER 1999: Effect of hospital restructuring on full time and part time nursing staff in Ontario. International Journal of Nursing Studies, 37(2000): 163-167.

BURNS, N \& GROVE, SK 2003: The practice of nursing research, conduct, critique and utilization. Philadelphia: Saunders.
BYDAWELL, M 2000: Managing people who don't come to work. People Dynamics. 18(4): 15-19.

COLLINS, K; JONES, ML; MCDONNELL,A; READ,S; JONES, R \& CAMERON, A 2000: Do new roles contribute to job satisfaction and retention of staff in nursing and professions allied to medicine? Journal of Nursing Management. 8(1): 3-12.

CONCISE OXFORD DICTIONARY 1995. $7^{\text {th }}$ edition. New York. Oxford.

DE BOER, EM: BAKKER,AB; SYROIT, JE \& SCHAUFELI, WB 2002: Unfaimess at work as a predictor of absenteeism. Journal of Organizational Behaviour. 23(2): 181-197.

ERICKSON, RJ; NICHOLSON, L \& RITTER, C 2000: Family influence on absenteeism: Testing an expanded process model. Journal of Vocational Behaviours. 57(2): 246-272.

GAUDINE,AP \& SAKS, AM 2001: The effect of an absenteeism feedback intervention on employee absence behavior. Journal of Organizational Behaviour, 2(1): 15-29.

GELLATLY, IR \& LUCHA, AA 1998: Personal and organizational determinants of perceived absence norms. Human Relations. 51(8): 1085-1102.

GRANT, G; NOLAN, M; MAGUIRE,B \& MELHUISH, IE 1995: Factors influencing job satisfaction among nurses. British Journal. 3(12): 615-620.

\section{HEMINGWAY, MA\& SMITH, CS 1999:}

Organisational climate and occupational stressors as predictors of withdrawal behaviours and injuries in nurses. Journal of Occupational Nursing. 72(3): 285-299.

HIRSCHFELD, RR; SCHMITT,LP \& BEDEIAN, AG 2002: Job-content perceptions, performance-reward expectancies, and absenteeism among low-wage public-sector clerical employees. Journal of Business and Psvchology, 16(4): 553-564.

JOHNSON, PR \& INDVIK, J 1997: The scourge of the workplace: Depression at work. Journal of Workplace Learning. 9(1): 1-5.

KASS, SJ; VODANOVICH, SJ \&
CALLENDER, A 2001: State-trait boredom: Relationship to absenteeism, tenure, and job satisfaction. Journal of Business and Psychology. 16(9): 317-327.

KAY, J 1999: Health promotion: ensuring the health of the nurse. Journal of Advanced Nursing. 13(18): 49-53.

MATRUNOLA, P 1996: Is there a relationship between job satisfaction and absenteeism? Journal of Advanced Nursing. 23: 827-834.

MCGILTON, KS \& PRINGLE, DM 1999: The effect of perceived and preferred control on nurses' job satisfaction in long term care environments. Research in Nursing and Health, 22(3): 252-261.

MCHUGH, M 2001: Employee absence: an impediment to organizational health in local government. International Journal of Public Sector Management. 14(1): 1-10.

MCNEESE-SMITH, DK 1997: The influence of manager behavior on nurses' job satisfaction, productivity, and commitment. Jona 27(9): 47-55.

MNGOMEZULU, T 2001: Global migration of nurses. Nursing Update. 25(9): 39 .

MZOLO, B 2001: Global migration of nurses: A vexing problem. Nursing Update, 25(9): 38.

PARKER, PA \& KULIK, JA 1995: Burnout, self- and supervisor-related job performance, and absenteeism among nurses. Journal of Behavioural Medicine. 18(6): 581-599.

PAYNE, D 1999: Recovery time. Nursing Times, 94(3): 14-15

POLIT, DF \& HUNGLER, BP 1997: Nursing research principles and methods. Philadelphia: Lippincott.

POUSETTE, A \& HANSE, JJ 2002: Job characteristics as a predictor of ill-health and sickness absenteeism in different occupational types - a multigroup structural equation modelling approach. Work and Stress. 16(3): 229-250.

QURESHI, K 2000: Case studies in nursing management: Strategies for managing staff time and attendance. 
Seminars for Nurse Managers. 8(4): 174 177.

ROWLAND, S \& ROWLAND, L 1997: Nursing administrative handbook. $4^{\text {th }}$ edition. Maryland: Aspen.

SAKSVIK, PO \& NYTRO, K 2001: Improving subjective health and reducing absenteeism in a natural work life-intervention. Scandinavian Journal of Psychology. 42 (1): 17-24.

SANTOS, SR \& COX, K 2000: Workplace adjustment and intergenerational differences between matures, boomers, and Xers. Nursing Economics. 18(1): 7-13.

SARUDI, D 2000: Inbox: Who's minding the hospital? Absenteeism soars. Health and Hospital Network. 74 (4): 14.

\section{SHADER, K; BROOME,ME; BROOME,} CD; WEST, ME \& NASH, M 2001: Factors influencing satisfaction and anticipated turnover for nurses in an academic medical center. Jona, 31(4): 210216.

SOUTH AFRICA (Republic) 1978: Regulation R 2598, Nursing Act (Act 50 of 1978, as amended). Pretoria: Government Printer.

SULLIVAN, EJ \& DECKER, PJ 1992: Effective management in nursing. California: Addison-Wesley Nursing.

TAUNTON, RL; HOPE, K; WOODS, CQ \& BOTT, MJ 1995: Predictors of absenteeism among hospital staff nurses. Nursing Economics. 13(4): 217-224.

TIME 10 March 2003: 42.

TRINKOFF, AM; STORR, CL \& LIPSCOMB JA 2001: Physically demanding work and inadequate sleep, pain medication use, and absenteeism in registered nurses. Journal of Occupational Environmental Medicine. 43(4): 355-363.

VAN DER WALT, R 1999: Don't take the ostrich approach to absenteeism. People Dynamics. 17(11): 48-51.

VAN DIERENDONCK, D; LE BLANC, PM \& VAN BREUKELEN, W 2001: Supervisory behavior, reciprocity and subordinates absenteeism. Leadership and Organizational Development Journal.
23(3): 1-9.

WESTMAN,M \& ETZION, D 2001: The impact of vacation and job stress on burnout and absenteeism. Psychology and Health. 16(5): 595-606.

WILLS, S 1999: Speaking out - job satisfaction and morale are the foremost factors affecting retention. Nursing Times. 95(38): 21.

WING, M 1999: Nursing makes you sick. Nursing Times. 95(7): 24-25.

WOOD, G 1998: Absenteeism: Worse workplace goodwill wanes. Productivity SA, 24(5): 26-28. 